\title{
Spectral Characteristics of Needle Array-Plate Dielectric Barrier Discharge Plasma and Its Activated Water
}

\author{
Yibing Li $\mathbb{D}^{1},{ }^{1}$ Zhiqing Song $\mathbb{D},{ }^{1,2}$ Tao Zhang $\mathbb{D}^{1},{ }^{1}$ Wenqian Xu $\mathbb{D}^{1},{ }^{1}$ Changjiang Ding $\mathbb{D}^{1,2}$ \\ and Hao Chen iD ${ }^{1,2}$ \\ ${ }^{1}$ College of Science, Inner Mongolia University of Technology, Hohhot 010051, China \\ ${ }^{2}$ Center for Energy Conservation and Emission Reduction in Fermentation Industry of Inner Mongolia Autonomous Region, \\ Hohhot 010051, China
}

Correspondence should be addressed to Zhiqing Song; zqsong@imut.edu.cn

Received 8 July 2021; Accepted 15 October 2021; Published 1 November 2021

Academic Editor: K.S.V. Krishna Rao

Copyright (c) 2021 Yibing Li et al. This is an open access article distributed under the Creative Commons Attribution License, which permits unrestricted use, distribution, and reproduction in any medium, provided the original work is properly cited.

The plasma-activated water (PAW), as a new environmentally friendly nonthermal processing technology, has attracted wide attention for its applications in agriculture, food, and biomedical fields. This paper used the needle array-plate dielectric barrier discharge (needle array-plate DBD) device to activate deionized water and prepare PAW simply and efficiently. It was found that the concentration of reactive oxygen and nitrogen species (RONS) generated in the process of needle array-plate DBD was large and varied. Especially in the wavelength range of $600-770 \mathrm{~nm}$, the spectral intensity is stronger. And, the ionic wind is more likely to interact with the deionized water. The changes in PAW parameters and UV/Vis spectra with treatment time were measured under different voltages and needle-dielectric plate distances. Results show that increasing discharge voltage or decreasing needledielectric plate distance increases the concentration of RONS, ionic wind speed, water evaporation, and conductivity of the PAW and decreases $\mathrm{pH}$. UV/Vis spectra results show that prolonged treatment time results in increased total absorbance and concentrations of $\mathrm{H}_{2} \mathrm{O}_{2}$ and $\mathrm{NO}_{3}^{-}$and that a new absorption peak appears at $210 \mathrm{~nm}$ in the UV/Vis spectra. When the wavelength is larger than $210 \mathrm{~nm}$, a redshifted new peak and color enhancement are observed. The seeds of Astragalus adsurgens Pall were treated by discharge plasma, PAW, and the combination of plasma and PAW. It was found that high voltage and long-time activated PAW could significantly increase the ROS level of seeds and seedlings after germination for 3 days, resulting in oxidative stress damage. The survival rate of seeds was lower than that under the half lethal dose. This paper provides a feasible device design for treating activated water in large quantities with high efficiency, which is important for the application of PAW and mutation breeding of $A$. adsurgens Pall.

\section{Introduction}

In recent years, the application of low-temperature plasmas has attracted interest. Due to the high content of water on Earth and some foods and organisms also contain a lot of water, the application research of discharge plasma in agriculture, food, and biomedical fields mostly involves the interaction between plasma and water. Therefore, the plasma device should be developed and designed. The interface physicochemical process should be regulated, and the activation of water by plasma should be studied. Plasma discharge can produce a large amount of reactive oxygen and nitrogen species (RONS) through the plasma discharge in water or water surface, and the physicochemical interaction between RONS and water is carried out to obtain the plasma-activated water (PAW). PAW has the characteristics of a high content of active components, good uniformity and fluidity, and low $\mathrm{pH}$, which refers to functional water [1], and has a wide range of applications without secondary pollution.

PAW is widely used in many fields, such as medicine, agriculture, and biology [2-7]. PAW can inactivate SARSCoV-2 [2] and has a positive effect on the growth of pea, wheat, and lentil seedlings [8-10]. PAW can also effectively 
kill Staphylococcus aureus [11], inhibit the growth of Fusarium oxysporum AF93247, and effectively inhibit the spoilage of green peppers and maintain its quality [12].

Existing plasma devices used to prepare PAW include the helium plasma jet device $[13,14]$, mesh electrode dielectric barrier discharge (DBD) device [15-17], dielectric barrier reactor equipment discharge device [8], cathode (needle) anode (copper ring) glass tube dielectric isolation discharge system [18], planar DBD [1], and coaxial DBD [19]. The main disadvantages of these discharge plasma devices are the small contact area between plasma and water, the high cost of helium gas, the low plasma concentration produced by helium plasma jet, and the unsuitability for mass processing. Given the wide application of PAW, its demand is increasing. A plasma device with a simple design, evident activation effect, low cost, and suitability for mass processing is urgently needed.

The needle-plate corona discharge device was widely used in promoting seed germination [20, 21], drying [22, 23], thawing [24], and other aspects. In order to improve the concentration of plasma active particles and highlight the effect of electric field on water, the DBD structure and the traditional needle array-plate corona discharge structure were combined, and a needle array-plate DBD device was used. The high-voltage needle electrode is a multineedle array, and the grounding aluminum plate electrode is covered with a $4 \mathrm{~mm}$ thick PMMA dielectric plate. The covering of the dielectric plate is not easy to break down, and a large adjustable voltage range, increased plasma concentration, and evident effect are observed. The plasma concentration is higher than that of other plasma emitters in the process of activating water by using a needle array-plate $\mathrm{DBD}$ device. And as the water is activated, the water surface produces vibration ripples. This is beneficial to the evaporation of water, the increased contact area between plasma and water, and enhanced activation ability. PAW with a longer activation time may be of significance to the mutation breeding of Astragalus adsurgens Pall.

\section{Materials and Methods}

\subsection{Plasma Discharge Setup and Diagnosis}

2.1.1. Needle Array-Plate DBD Device. The needle arrayplate DBD device was used in this study (Figure 1). The power supply of the experimental device was AC. The frequency was $50 \mathrm{~Hz}$, and the voltage was continuously adjustable from $0 \mathrm{kV}$ to $50 \mathrm{kV}$. The high-voltage power supply is a transformer; the high-voltage electrode was composed of a needle array with a length of $2 \mathrm{~cm}$; the diameter of the needle is $1.56( \pm 0.02) \mathrm{mm}$, and horizontal and vertical spacing of $4 \mathrm{~cm}$. The grounding end was a planar aluminum plate covered with a PMMA dielectric plate with a thickness of $4 \mathrm{~mm}$. The whole-electrode system was closed using a dark box to create a relatively closed experimental environment, which could allow air to enter and effectively reduce the diffusion speed of the discharge plasma to the outside world for full interaction with water.
2.1.2. Plasma Diagnosis. The SLR camera (Nikon D7000, Japan) was used to capture images of the discharge conditions under different conditions. The plasma emission spectra under different voltages and needle-dielectric plate distances were analyzed using a spectrometer (Kymera ANDOR 328i) to diagnose the variety and concentration of particles in the plasma produced by the needle array-plate DBD (spectrometer focal length: $328 \mathrm{~mm}$; image resolution: $0.44-0.31 \mathrm{~nm}$ continuously adjustable; detector type: DH334T-16F-E3).

\subsection{Experimental Methods}

2.2.1. Discharge Plasma Treatment. The deionized water (UPR-I-60L UPR pure water manufacturing system, Sichuan) was allowed to stand in the air for $12 \mathrm{~h}$. Thus, the concentration of dissolved gas in the deionized water was equilibrated with that in the air to ensure that the concentration of dissolved gas was constant during the experiment [25]. Deionized water $(50 \mathrm{ml})$ was collected from the measuring cylinder and placed into a polypropylene Petri dish with an inner diameter of $14 \mathrm{~cm}$. The mass of deionized water was accurately weighed using an electronic balance with an accuracy of $0.0001 \mathrm{~g}$.

Firstly, when the distance between the needle tip and the dielectric plate is constant and the voltage is changed, the change of PAW indexes with time is analyzed: the distance between the needle tip and the dielectric plate was $4 \mathrm{~cm}$; $50 \mathrm{ml}$ of deionized water was poured into a Petri dish with an inner diameter of $14 \mathrm{~cm}$; the liquid level depth was only $0.325 \mathrm{~cm}$; and the distance from the needle tip to the water surface was $3.675 \mathrm{~cm}$. Using $15 \mathrm{kV}, 20 \mathrm{kV}$, and $25 \mathrm{kV}$ voltages, six parallel Petri dishes with deionized water were placed under each voltage gradient, and one Petri dish was taken out every 10 minutes for measurement; each experiment was repeated 3 times.

When the voltage is constant and the distance from the needle tip to the dielectric plate is changed, the change of PAW indexes with time is analyzed: the voltage was determined to be $20 \mathrm{kV}$, and the distance between the needle tip and dielectric plate was $3 \mathrm{~cm}, 4 \mathrm{~cm}$, and $5 \mathrm{~cm}$ to treat deionized water; at this time, the distances from the needle tip to the water surface were $2.675 \mathrm{~cm}, 3.675 \mathrm{~cm}$, and $4.675 \mathrm{~cm}$, respectively. Six parallel Petri dishes with deionized water were placed under the gradient of each needle-dielectric plate distances, and one Petri dish was taken out every 10 minutes for measurement; each experiment was repeated 3 times.

2.2.2. Ionic Wind. The ionic wind speed under the tip of the needle under different experimental conditions was measured using a thermal anemometer probe (405i, Ruice Electronics Technology Co. Ltd., Guangzhou, China; a schematic diagram is shown in Figure 1). Each experiment was repeated 10 times independently and averaged.

2.2.3. Evaporation Rate. PAW of six dishes were treated under the same experimental conditions, and one dish was taken out every 10 minutes. The PAW after treatment was 


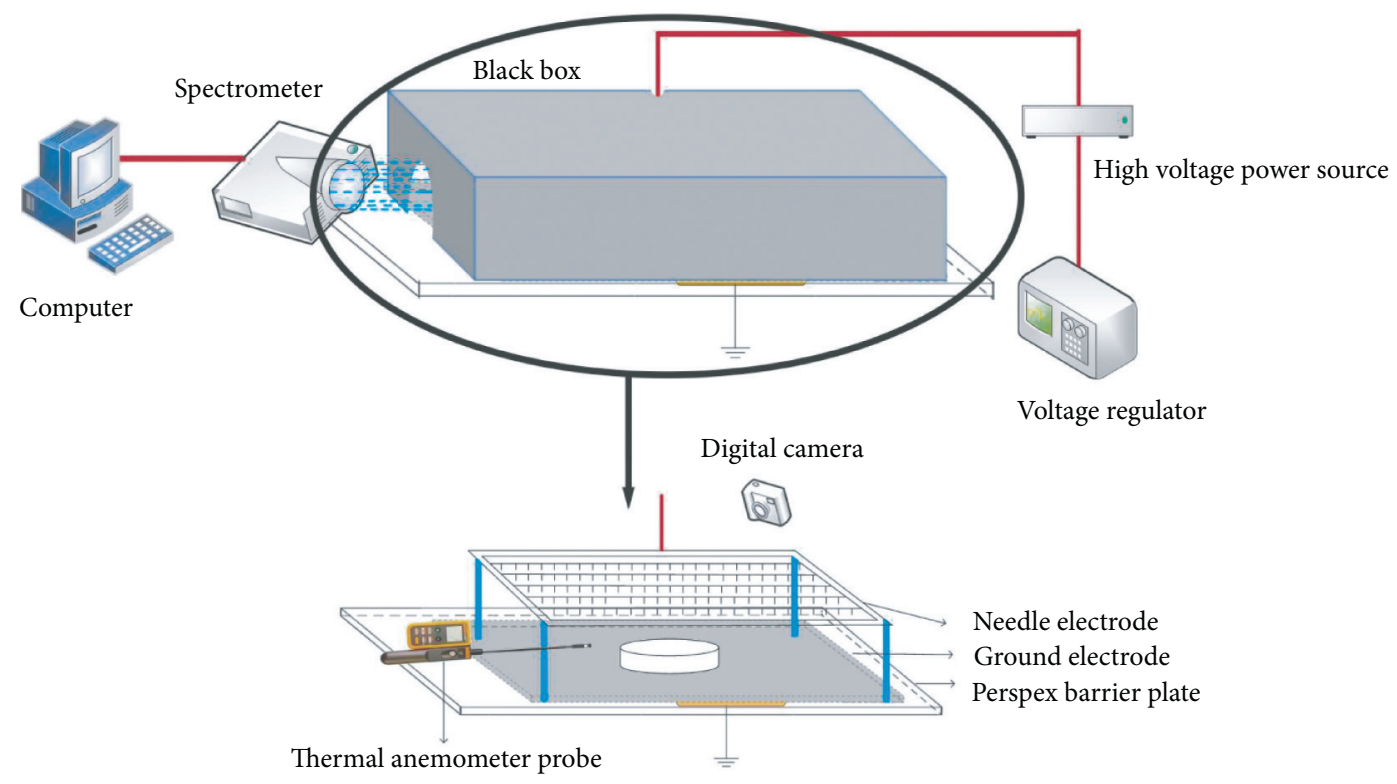

FIgURE 1: Experimental device diagram.

accurately weighed and marked using an electronic balance with an accuracy of $0.0001 \mathrm{~g}$. The evaporation rate of treated water under different conditions was calculated using the following formula:

$$
V=\frac{m^{\prime}-m}{S t}
$$

where $V$ is the evaporation rate, $m$ ' is the quality of the PAW, $m$ is the mass of untreated deionized water, $S$ is crosssectional area of the Petri dish, and $t$ is the processing time.

2.2.4. $p H$. Part of the weighed PAW was taken out, and its $\mathrm{pH}$ was measured using a $\mathrm{pH}$ meter (PHS-2F Shanghai) with an accuracy of 0.01 .

2.2.5. Electrical Conductivity. A part of PAW was collected, and its conductivity was measured using a conductivity meter (DDS-307A Shanghai) with an accuracy of 0.1.

2.2.6. $U V / V i s$ Spectra. Within $30 \mathrm{~min}$ after water treatment, the UV/Vis spectra of PAW were mapped using a micro$\mathrm{UV} / \mathrm{V}$ is spectrophotometer (NanoDrop One $\mathrm{C}^{\mathrm{C}}$ ). The liquid to be tested was injected into a $10 \mathrm{~mm}$ quartz cuvette. The optical path length was $10 \mathrm{~mm}$, and the absorbance in the wavelength range of $190-850 \mathrm{~nm}$ was measured.

2.2.7. Spectral Analysis. The concentration of RONS could be determined from the spectra by using the Beer-Lambert law:

$$
\mathrm{Abs}_{\lambda}=\varepsilon l c,
$$

where $\varepsilon$ is the molar absorptivity of the chemical species at a certain wavelength $\lambda, l$ is the optical path length $(10 \mathrm{~mm})$, and $c$ is the concentration of RONS.
The total RONS concentrations in the PAW could be obtained by integrating the absorbance area at the wavelengths of 190-340 $\mathrm{nm}$ in the UV/Vis spectra [26]. The total RONS concentrations could be calculated in accordance with the following formula:

$$
\text { total absorbance } \approx \int_{190 \mathrm{~nm}}^{340 \mathrm{~nm}} \operatorname{Abs}(\lambda) \mathrm{d} \lambda \text {. }
$$

2.2.8. Concentrations of $\mathrm{H}_{2} \mathrm{O}_{2}, \mathrm{NO}_{2}^{-}$, and $\mathrm{NO}_{3}^{-}$. The needle array-plate $\mathrm{DBD}$ generated a lot of plasma, which activated the water through diffusion and interaction between ionic wind and water. The activated water contained $\mathrm{H}_{2} \mathrm{O}_{2}, \mathrm{NO}_{2}^{-}$, $\mathrm{NO}_{3}^{-}$, and other particles. The main chemical reaction pathways are shown in Figure 2.

(1) Concentration of $\mathrm{H}_{2} \mathrm{O}_{2}$. Studies showed that only $\mathrm{H}_{2} \mathrm{O}_{2}$ contributes to the absorption spectra above $250 \mathrm{~nm}$ for the long-lived particles in PAW. Therefore, $\mathrm{H}_{2} \mathrm{O}_{2}$ absorption was separated from total absorption. The concentration of $\mathrm{H}_{2} \mathrm{O}_{2}$ in the solution could be calculated using the absorbance of PAW at 250 and $255 \mathrm{~nm}$ [27].

In accordance with the Beer-Lambert law, the concentration of $\mathrm{H}_{2} \mathrm{O}_{2}$ could be calculated using the absorbance values at 250 and $255 \mathrm{~nm}$ through the following formula:

$$
\begin{aligned}
& \operatorname{Abs}_{250}=\varepsilon_{250}\left(\mathrm{H}_{2} \mathrm{O}_{2}\right) l=7.247 \times 10^{-4} \times n\left(\mathrm{H}_{2} \mathrm{O}_{2}\right), \\
& \mathrm{Abs}_{255}=\varepsilon_{255}\left(\mathrm{H}_{2} \mathrm{O}_{2}\right) l=5.315 \times 10^{-4} \times n\left(\mathrm{H}_{2} \mathrm{O}_{2}\right),
\end{aligned}
$$

where $n\left(\mathrm{H}_{2} \mathrm{O}_{2}\right)$ is the concentration of $\mathrm{H}_{2} \mathrm{O}_{2}$ in the solution; $A b s_{250}$ and $A b s_{255}$ are the absorbance values at 250 and $255 \mathrm{~nm}$, respectively; and $l$ is the optical path length $(10 \mathrm{~mm})$. The concentration of $\mathrm{H}_{2} \mathrm{O}_{2}$ was calculated using the following equation: 


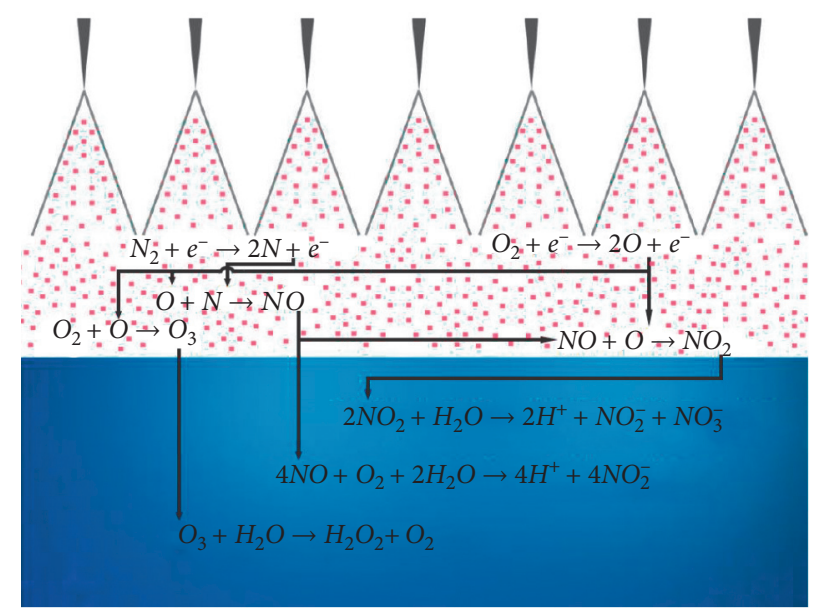

Figure 2: Chemical reaction pathway of plasma-activated water.

$$
\begin{aligned}
n\left(\mathrm{H}_{2} \mathrm{O}_{2}\right) & =\left[\frac{\mathrm{Abs}_{250}}{\left(7.247 \times 10^{-4}\right)}\right] \\
& \text { or }\left[\frac{\mathrm{Abs}_{255}}{\left(5.315 \times 10^{-4}\right)}\right] .
\end{aligned}
$$

(2) Concentration of $\mathrm{NO}_{2}^{-}$. The soil and water $\mathrm{NO}_{2}^{-}$content detection kit (Solarbio Beijing) was used. Under acidic conditions, $\mathrm{NO}_{2}^{-}$reacted with 3-aminobenzene sulfonic acid to form diazo compound, which then reacted with $\mathrm{N}-1$ naphthylethylenediamine dihydrochloride to form purplish azo compounds. A characteristic absorption peak was observed at $540 \mathrm{~nm}$. The concentration of $\mathrm{NO}_{2}^{-}$could be calculated using the absorption peak at $540 \mathrm{~nm}$.

(3) Concentration of $\mathrm{NO}_{3}^{-}$. Liu et al. studied the concentration of RONS in PAW and found that at 230 and $235 \mathrm{~nm}$, the absorbance of PAW measured using the UV/Vis spectrophotometer was the sum of $\mathrm{H}_{2} \mathrm{O}_{2}, \mathrm{NO}_{2}^{-}$, and $\mathrm{NO}_{3}^{-}$ concentrations. The concentration of $\mathrm{NO}_{3}^{-}$could be calculated in accordance with the concentrations of $\mathrm{H}_{2} \mathrm{O}_{2}$ and $\mathrm{NO}_{2}^{-}$by using the following equations [27]:

$$
\begin{aligned}
\mathrm{Abs}_{\lambda} & =\alpha n\left(\mathrm{NO}_{3}^{-}\right)+\beta n\left(\mathrm{NO}_{2}^{-}\right)+\varepsilon n\left(\mathrm{H}_{2} \mathrm{O}_{2}\right), \\
\mathrm{Abs}_{230} & =0.0085 \times n\left(\mathrm{NO}_{3}^{-}\right)+0.0228 \times n\left(\mathrm{NO}_{2}^{-}\right)+0.0020 \times n\left(\mathrm{H}_{2} \mathrm{O}_{2}\right), \\
\mathrm{Abs}_{235} & =0.0032 \times n\left(\mathrm{NO}_{3}^{-}\right)+0.0113 \times n\left(\mathrm{NO}_{2}^{-}\right)+0.0015 \times n\left(\mathrm{H}_{2} \mathrm{O}_{2}\right),
\end{aligned}
$$

where $\alpha, \beta$, and $\varepsilon$ are the molar absorptivity coefficients and could be obtained by fitting the concentration and absorbance functions of a single particle at a specified wavelength. The $A b s_{\lambda}$ in the vector is the absorption at wavelength $\lambda$.

\subsubsection{Effects of $P A W$ and Discharge Plasma on Seeds of} Astragalus adsurgens Pall. The seeds of A. adsurgens Pall were treated with $4 \mathrm{~cm}$ needle-dielectric plate distances, $25 \mathrm{kV}$ voltage, $60 \mathrm{~min}$ treatment time, and PAW under the same conditions. The voltage of plasma treatment was $25 \mathrm{kV}$; the needle-dielectric plate distance was $4 \mathrm{~cm}$; and the treatment time was $60 \mathrm{~min}$. PAW for seed treatment was also obtained under these conditions. The selected seeds were evenly placed in a Petri dish with a diameter of $9 \mathrm{~cm}$ and 50 seeds per dish. Without any treatment, the deionized water culture group (control group) was marked as CK; after discharge plasma treatment, the deionized water culture group was marked as
Plasma; without discharge plasma treatment, PAW culture group was marked as PAW; the coculture group of discharge Plasma and PAW was marked as Plasma + PAW.

The selected seeds were placed in Petri dishes with three layers of filter paper. Every other day, deionized water was added to the Petri dishes of the CK and Plasma groups, and PAW was added to the PAW and Plasma + PAW groups to maintain sufficient water. The seeds were placed in a light incubator at a constant temperature of $24^{\circ} \mathrm{C}$. After the seeds were germinated, the light incubator was irradiated with 100 lux light, continuous illumination for $14 \mathrm{~h}$, and darkness for $10 \mathrm{~h}$. The survival rate was counted 6 days later. The formula of seed survival rate is as follows:

$$
S=\frac{n_{6}}{N} \times 100 \%
$$

where $S$ is the survival rate, $N$ is the total number of seeds, and $n_{6}$ is the number of germination on the 6 th day. 
2.2.10. Seedling ROS Content Test. From the same treated seedlings, $1.5 \mathrm{~g}$ was randomly selected on the $3 \mathrm{rd}$ and 6 th day of inoculation, and the ROS was measured after the ice bath was ground. The substrate used for the assay was 20,70Dichlorodihydrofluorescein diacetate. The sample to be tested was reacted with $10 \mathrm{mM}$ CM-H2DCFDA at $25^{\circ} \mathrm{C}$ for $30 \mathrm{~min}$ in the dark according to the method of Babu et al. [28]. The sample was then placed in a 96-well plate containing $100 \mu \mathrm{L}$ of distilled water in the dark and then put into a microplate reader (SpectraMax I3, Molecular Devices (MD) Corporation, USA). The excitation intensity of $530 \mathrm{~nm}$ was detected by excitation with an excitation light of $485 \mathrm{~nm}$. This was repeated six times or more.

\section{Results}

\subsection{Plasma Diagnosis}

3.1.1. Plasma Discharge under Different Conditions. In dark conditions, the needle array-plate DBD can produce evident purple light (Figure 3).

Figure 3(a) shows the plasma discharge pattern when the needle-dielectric plate spacing is $4 \mathrm{~cm}$ and the voltage is changed. In Figure 3(a), the plasma discharge phenomenon at a voltage of $25 \mathrm{kV}$ is most evident, followed by that at a voltage of $20 \mathrm{kV}$, and weakest at a voltage of $15 \mathrm{kV}$. At $15 \mathrm{kV}$, only faint light can be seen.

Figure 3(b) shows the plasma emission diagram observed at a voltage of $20 \mathrm{kV}$, and the needle-dielectric plate spacing is changed. The plasma discharge at needle-dielectric plate distance of $3 \mathrm{~cm}$ is most evident, followed by that at needle-dielectric plate distance of $4 \mathrm{~cm}$, and weakest at needle-dielectric plate distance of $5 \mathrm{~cm}$.

The plasma discharge increases with increasing voltage and decreasing needle-dielectric plate distance.

\subsubsection{Variation of Ionic Wind under Different Conditions.} Figure 4(a) shows the measurement results of ionic wind speed under different voltages. The ionic wind speed increases linearly with increasing voltage. Figure 4(b) shows the measurement results of ionic wind speed under different needle-dielectric plate distances. The ionic wind velocity decreases with increasing needle-dielectric plate distance.

\subsubsection{Diagnosis of Plasma Emission Spectra under Different} Conditions. The plasma emission spectra are shown in Figure 5. The concentration of RONS produced in the process of needle array-plate DBD is high, and many kinds exist. $\mathrm{O}(715.6$ and $799.8 \mathrm{~nm}), \mathrm{N}(674.4$ and $631.6 \mathrm{~nm}), \mathrm{NO}_{2}$ (594.1 nm), $\mathrm{N}^{+}(426 \mathrm{~nm}), \mathrm{N}_{2}^{+}(393.4 \mathrm{~nm}), \mathrm{N}_{2}^{*}$ (337.3, 357.3, and $315.8 \mathrm{~nm})$, and $\mathrm{NO}_{-\gamma}(297 \mathrm{~nm})$ can be clearly observed in the emission spectra. The $\mathrm{N}(3 \mathrm{p}-3 \mathrm{~s})$ and $\mathrm{O}(3 \mathrm{p}-3 \mathrm{~s})$ spectra increase significantly in the wavelength range of $600-900 \mathrm{~nm}$, and the peak height increases significantly with increasing voltage.

The spectral intensity of the emission lines of $\mathrm{O}, \mathrm{NO}_{2}$, $\mathrm{N}_{2}^{*}, \mathrm{~N}^{+}, \mathrm{N}_{2}^{+}$, and $\mathrm{NO}_{-\gamma}$ in Figure 6(a) increases with increasing voltage. The spectral intensity of these particle lines in Figure 6(b) decreases as the needle-dielectric plate distance increases. This result corresponds to the phenomenon observed in Figure 3, thereby proving the change in plasma concentration.

\subsection{Analysis of $P A W$}

3.2.1. Evaporation Rate. Figure 4 shows that under the same conditions, a high voltage and low needle-dielectric plate distance result in high ionic wind speed. Moreover, a high voltage and low needle-dielectric plate distance result in a fast evaporation rate of water due to the action of ionic wind and a high-voltage electric field (Figure 7).

3.2.2. $\mathrm{pH}$ and Conductivity of $P A W$. The initial $\mathrm{pH}$ and conductivity of the deionized water are 6.54 and $2.93 \mu \mathrm{S} / \mathrm{cm}$, respectively. The $\mathrm{pH}$ of $\mathrm{PAW}$ decreases with increasing treatment time, and the minimum value can be below 3 . After 10-30 min treatment, the $\mathrm{pH}$ decreases sharply, and after $30 \mathrm{~min}$, the $\mathrm{pH}$ value decreases slowly and tends to be stable. When the needle-dielectric plate distance is $4 \mathrm{~cm}$, a high voltage results in low $\mathrm{pH}$ of PAW. At a constant voltage of $20 \mathrm{kV}$, decreasing needle-dielectric plate distance results in low $\mathrm{pH}$ of PAW (Figure 8).

The electrical conductivity of PAW increases sharply after treatment, especially with increasing voltage. At needledielectric plate distance of $4 \mathrm{~cm}$ and a voltage of $25 \mathrm{kV}$, the conductivity increases linearly. The highest conductivity obtained is around $1,400 \mu \mathrm{S} / \mathrm{cm}$. At a voltage of $20 \mathrm{kV}$, needle-dielectric plate distance results in high conductivity change in PAW (Figure 9).

3.2.3. $U V / V$ is Spectra of PAW. At the needle-dielectric plate distance of 4 and $5 \mathrm{~cm}$, the voltages are 15 (Figure 10(a)) and 20 (Figure $10(\mathrm{e})) \mathrm{kV}$, respectively. The UV/Vis spectra of these two images, that is, same contours and peak positions, are similar to those obtained by $\mathrm{Oh}$ et al. [25] and Liu et al. [27]. At the needle-dielectric plate distance of 4 and $3 \mathrm{~cm}$, a voltage of $20 \mathrm{kV}$ (Figures 10(b) and 10(d)), and treatment of $10 \mathrm{~min}$, the UV/Vis spectra are the same as those observed in previous studies. After $20 \mathrm{~min}$ of treatment, a new peak appears in the UV/Vis spectra. At this time, with increasing processing time, the spectral curve of the wavelength from 190 to $210 \mathrm{~nm}$ has no evident change. However, at a wavelength higher than $210 \mathrm{~nm}$, a new peak with a redshift and color enhancement is observed with increased processing time. In Figure 10(c), at the needle-dielectric plate distance of $4 \mathrm{~cm}$, a voltage of $25 \mathrm{kV}$, and increased treatment time, the phenomena of redshift and color enhancement are evident.

3.2.4. Total Absorbance of RONS. Figure 11 shows the changes in the total absorbance of PAW obtained under different conditions. As the treatment time increases, the total absorbance of PAW increases. At constant the needledielectric plate distance, increased voltage results in increased total absorbance. At constant voltage, decreasing the 




(a)



(b)

Figure 3: Plasma discharge diagrams at (a) needle-dielectric plate distance of $4 \mathrm{~cm}$ and voltages of 15, 20, and $25 \mathrm{kV}$ and (b) voltage of $20 \mathrm{kV}$ and needle-dielectric plate distances of 3,4 , and $5 \mathrm{~cm}$.

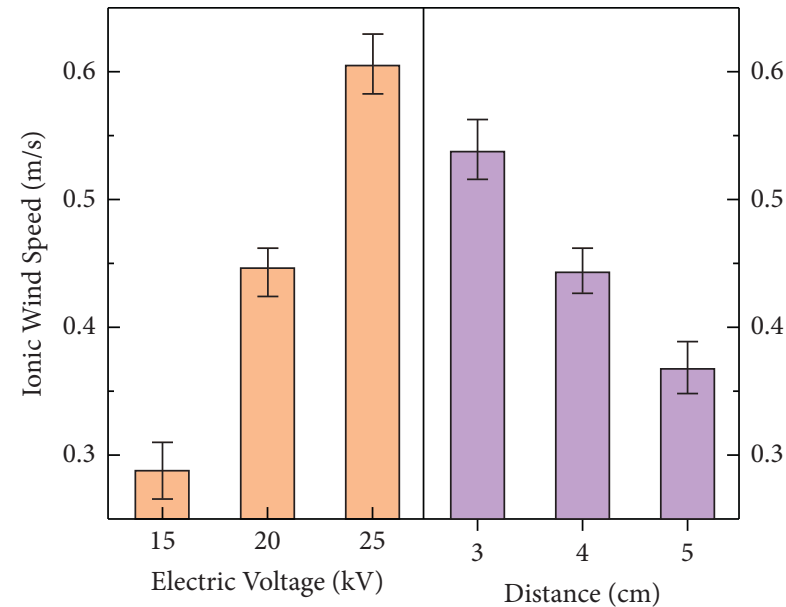

Figure 4: Ionic wind speeds at (a) needle-dielectric plate distance of $4 \mathrm{~cm}$ and voltages of 15,20 , and $25 \mathrm{kV}$ and (b) voltage of $20 \mathrm{kV}$ and needle-dielectric plate distances of 3,4 , and $5 \mathrm{~cm}$.

needle-dielectric plate distance results in increased total absorbance. The increased total absorbance indicates that the concentration of components in PAW is increasing.

3.2.5. Concentrations of $\mathrm{H}_{2} \mathrm{O}_{2}, \mathrm{NO}_{2}^{-}$, and $\mathrm{NO}_{3}^{-}$. (1) Concentration of $\mathrm{H}_{2} \mathrm{O}_{2}$. Figure 12 shows the concentration of $\mathrm{H}_{2} \mathrm{O}_{2}$ calculated in accordance with equations (4)-(6). Increasing treatment time results in increasing $\mathrm{H}_{2} \mathrm{O}_{2}$ concentration in PAW. At constant needle-dielectric plate distance, a high voltage results in high $\mathrm{H}_{2} \mathrm{O}_{2}$ concentration. At constant voltage, a small needle-dielectric plate distance results in high $\mathrm{H}_{2} \mathrm{O}_{2}$ concentration, and the highest concentration is $60 \mathrm{mg} / \mathrm{L}$.

(2) Concentration of $\mathrm{NO}_{2}^{-}$. When the water is activated at the needle-dielectric plate distance of $4 \mathrm{~cm}$ and voltage of $15 \mathrm{kV}$ and at the needle-dielectric plate distance of $5 \mathrm{~cm}$ and voltage of $20 \mathrm{kV}$, the $\mathrm{NO}_{2}^{-}$concentration increases with prolonged treatment time. When the water is activated at the

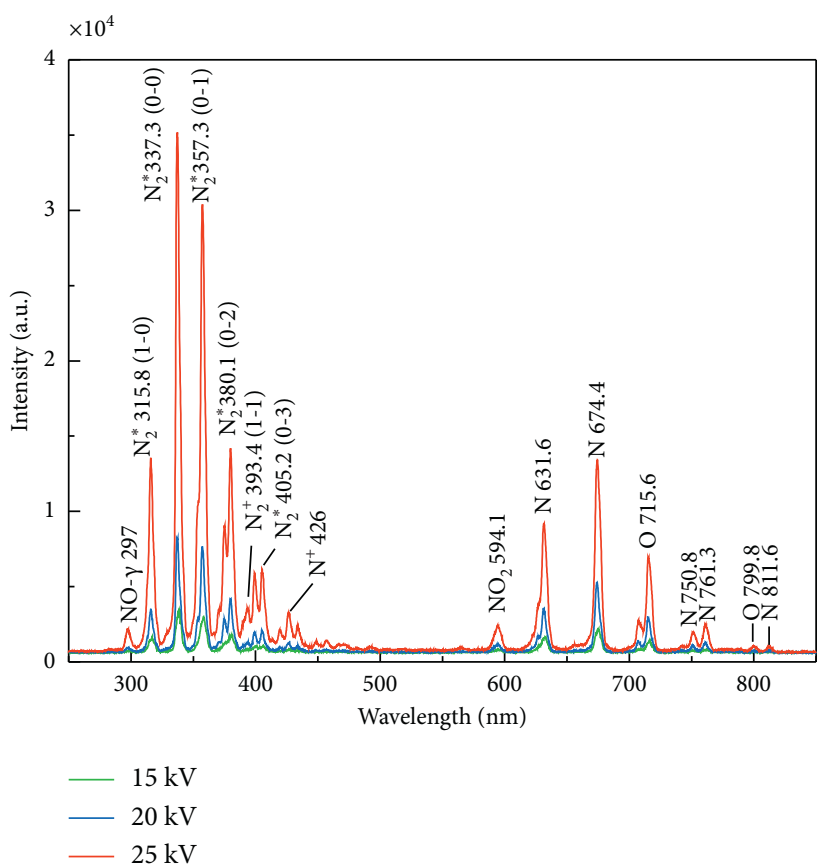

Figure 5: Plasma emission spectra.

needle-dielectric plate distance of 4 and $3 \mathrm{~cm}$ and voltage of $20 \mathrm{kV}$, the $\mathrm{NO}_{2}^{-}$concentration first increases and then decreases with increasing treatment time. At the needle-dielectric plate distance of $4 \mathrm{~cm}$, voltage of $25 \mathrm{kV}$, and activation time of $10 \mathrm{~min}$, the $\mathrm{NO}_{2}^{-}$concentration reaches $1.22 \mathrm{mg} / \mathrm{L}$ and decreases with prolonged time. The lowest $\mathrm{NO}_{2}^{-}$concentration reaches $0.29 \mathrm{mg} / \mathrm{L}$ (Figure 13).

(3) Concentration of $\mathrm{NO}_{3}^{-}$. In Figure 14, the $\mathrm{NO}_{3}^{-}$concentration shows the same change pattern as the $\mathrm{H}_{2} \mathrm{O}_{2}$ concentration. The concentration of $\mathrm{NO}_{3}^{-}$in $\mathrm{PAW}$ increases with increasing treatment time, and at constant needle-dielectric plate distance, a high voltage results in high $\mathrm{NO}_{3}^{-}$ concentration. At a voltage of $25 \mathrm{kV}$, the $\mathrm{NO}_{3}^{-}$concentration is $24.57 \mathrm{mg} / \mathrm{L}$. At constant, the needle-dielectric plate 


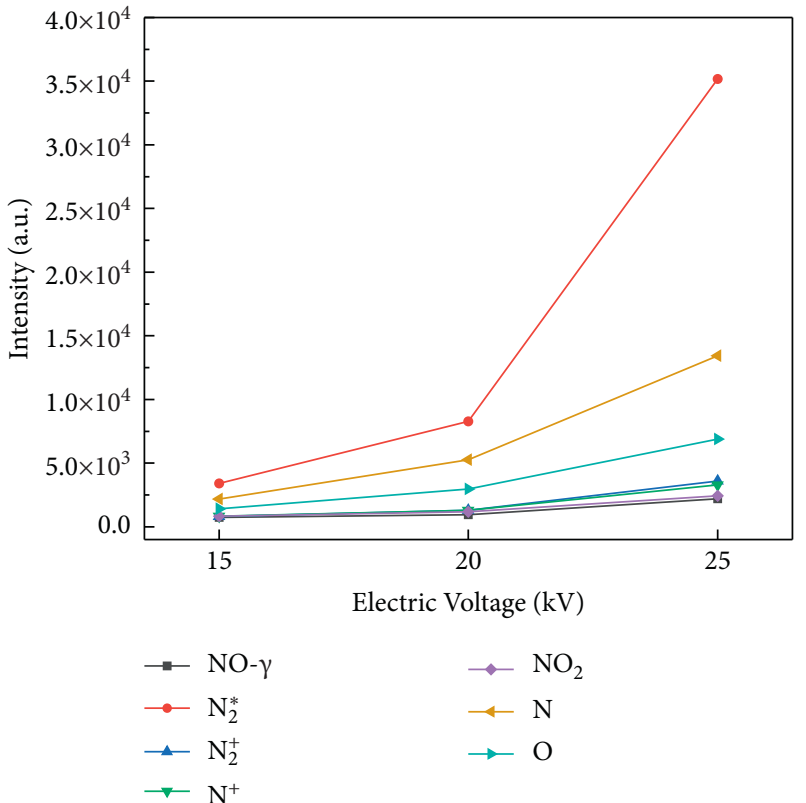

(a)

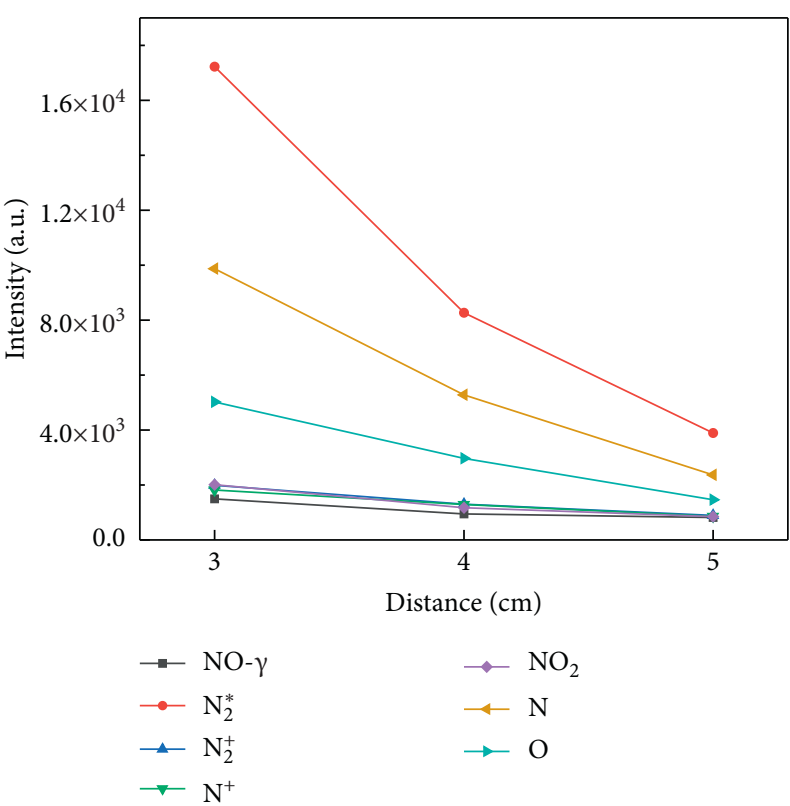

(b)

Figure 6: Plasma emission intensities at (a) needle-dielectric plate distance of $4 \mathrm{~cm}$ and voltages of 15, 20, and $25 \mathrm{kV}$ and (b) voltage of $20 \mathrm{kV}$ and needle-dielectric plate distances of 3,4 , and $5 \mathrm{~cm}$.

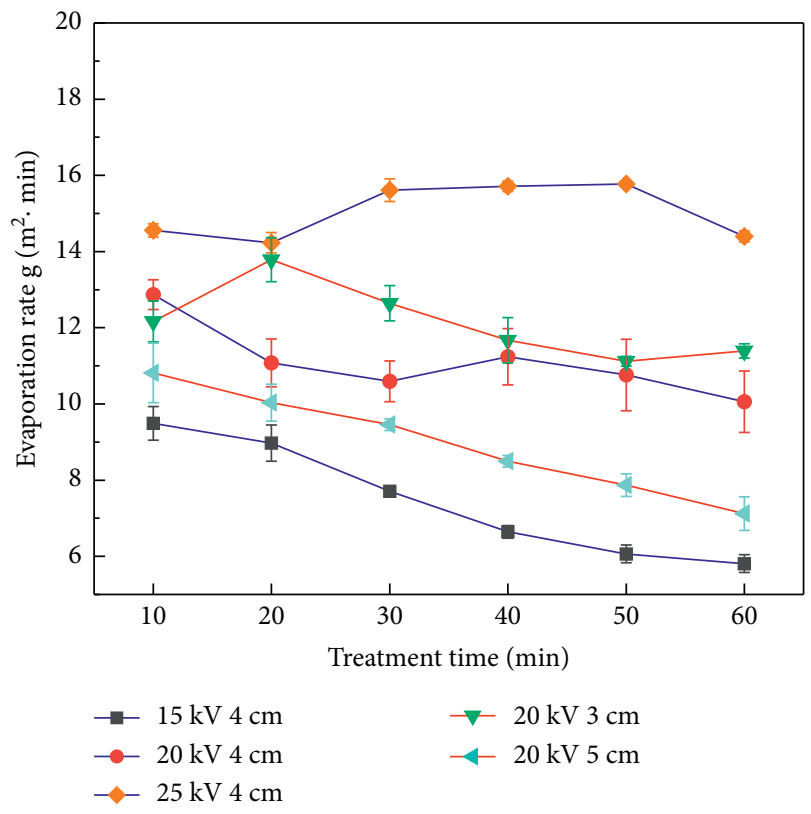

FIgURE 7: Evaporation rates at voltages of 15,20 , and $25 \mathrm{kV}$ and needle-dielectric plate distance of $4 \mathrm{~cm}$ and voltage of $20 \mathrm{kV}$ and needle-dielectric plate distance of $3 \mathrm{~cm}$ and $5 \mathrm{~cm}$.

distance results in high $\mathrm{NO}_{3}^{-}$concentration. At the needledielectric plate distance of $3 \mathrm{~cm}$, the $\mathrm{NO}_{3}^{-}$concentration is highest (reaching $135.65 \mathrm{mg} / \mathrm{L}$ ).

3.2.6. Survival of Astragalus adsurgens Pall Seeds. In Figure 15, the survival rate of the Plasma group was slightly lower than that of the CK group, but there was no significant difference between the two groups. The survival rate of the two groups treated with PAW was significantly reduced, reaching the half lethal dose, which was significantly different from that of the CK group. The survival rate of the Plasma + PAW group decreased most significantly. There was no significant difference between the PAW group and the Plasma + PAW group, which indicated that the mortality of the two groups increased and the survival rate decreased mainly due to the effect of PAW.

3.2.7. ROS Content Changes. As shown in Figure 16, the ROS content after treatment on the 3rd day after inoculation was lower than that of the control group; the content of ROS in the Plasma + PAW group was higher than that in other groups; and there was a significant difference between the Plasma + PAW group and other groups. On the 6th day after inoculation, the ROS content in each group was lower than on the 3rd day, the content of ROS in the treatment group was significantly lower than that in the control group.

\section{Discussion}

In the process of plasma discharge, the plasma concentration increases with increasing voltage and air ionization degree. In addition, when the needle-dielectric plate distance was adjusted, a small needle-dielectric plate distance and a high voltage result in high plasma concentration. The discharge phenomenon diagram shows that a high voltage and a small needle-dielectric plate distance result in an evident plasma emission phenomenon. Increasing voltage and decreasing needle-dielectric plate distance result in linearly increasing ionic wind speed. The ionic wind refers to the plasma 




Figure 8: The needle-dielectric plate distance of $4 \mathrm{~cm}$ and $\mathrm{pH}$ at voltages of 15,20 , and $25 \mathrm{kV}$ and the needle-dielectric plate distance of 3 and $5 \mathrm{~cm}$ and $\mathrm{pH}$ at a voltage of $20 \mathrm{kV}$.

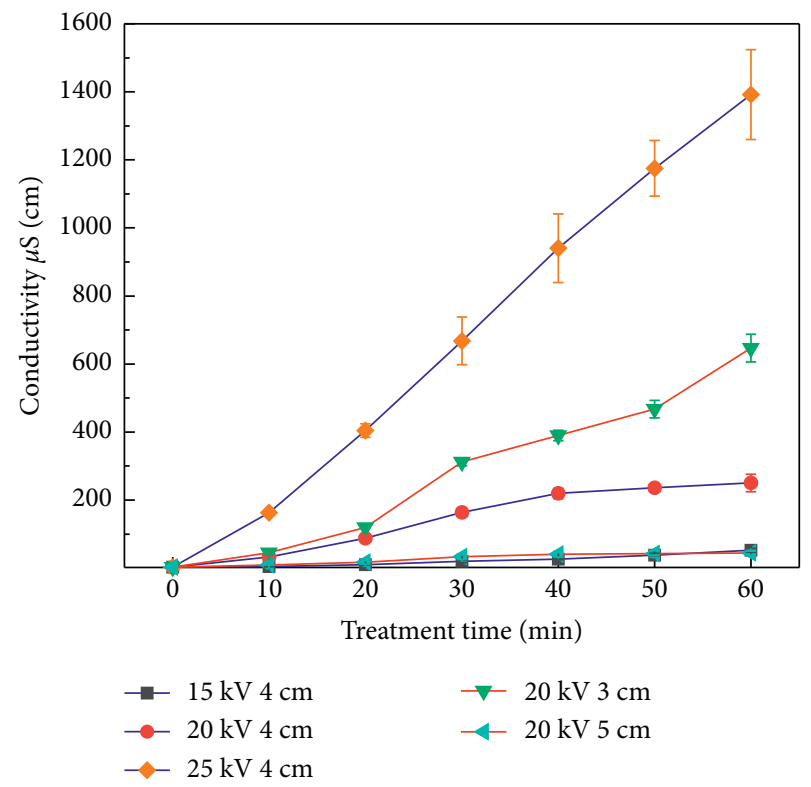

FIGURE 9: Conductivity values at needle-dielectric plate distance of $4 \mathrm{~cm}$ and voltages of 15,20 , and $25 \mathrm{kV}$ and needle-dielectric plate distance of 3 and $5 \mathrm{~cm}$ and voltage of $20 \mathrm{kV}$.

flowing in space and RONS. In addition to the RONS in the ionic wind dissolving into the water to activate the water, the spatial flow of RONS plays an important role in the process of needle array-plate DBD activation of water. First, the increase in ionic wind speed can improve the evaporation rate of water and then increase the concentration of RONS in PAW, which can improve the activation efficiency of PAW. Second, during treatment, ionic wind collides with water to form waves on the water surface. Considering the fluctuation in water, many RONS are dissolved into the water, and the water reacts. Compared with other devices, the discharge plasma generated makes the water active by diffusion and penetration, and the activation effect is evident.

In the plasma emission spectra, the plasma generated by the needle array-plate DBD contains $\mathrm{O}, \mathrm{NO}_{2}, \mathrm{~N}_{2}{ }^{*}, \mathrm{~N}^{+}, \mathrm{N}_{2}{ }^{+}$, $\mathrm{NO}_{-\gamma}$, and other particles, and the concentration of these particles also increases with increased discharge voltage or decreased needle-dielectric plate distance; this law can be proved by increasing the intensity of plasma emission spectrum. The oxidation potential of $\mathrm{O}$ is $2.42 \mathrm{~V}$, and $\mathrm{O}$ is one of the active oxygen particles with strong oxidation potential and plays an important role in the activation process of water. The analysis of the spectra shows that the intensity of plasma emission spectra produced by the needle array-plate DBD is higher than that of other plasma discharge devices commonly used in recent years, for example, DC plasma jet system studied by Deng et al. [29] and reverse discharge systems studied by Czech et al. [30]. Although the atmospheric pressure plasma jet device studied by Chen et al. has a high intensity in the wavelength range of $300-450 \mathrm{~nm}$; its intensity in the wavelength range of $590-810 \mathrm{~nm}$ is far lower than that of the experimental method used in this paper; and the content of $\mathrm{O}$ is low. Therefore, compared with other plasma emitters, the needle array-plate DBD has the advantages of large plasma concentration and rich plasma types.

With increasing voltage and treatment time, decreased needle-dielectric plate distance, decreased $\mathrm{pH}$ of PAW, and increased conductivity are observed. Changes in $\mathrm{pH}$ and conductivity are caused by increased treatment time, plasma concentration, and ionic wind speed. The UV/Vis spectra of PAW show that the UV/Vis spectra are basically the same as those obtained by previous studies at needle-dielectric plate distance of $4 \mathrm{~cm}$ and voltage of $15 \mathrm{kV}$ and at needle-dielectric plate distance of $5 \mathrm{~cm}$ and voltage of $20 \mathrm{kV}$. However, with increasing discharge voltage, decreasing needle-dielectric plate distance, and prolonged treatment time, a new peak appears in the UV/Vis spectra. In other words, a high concentration of discharge plasma and long treatment time results in the occurrence of the chemical change of PAW and probable production of new substances. After a new peak appears, with increasing treatment time, the UV/Vis spectra curves from 190 to $210 \mathrm{~nm}$ have no evident change and are close to coincidence. However, when the wavelength is larger than $210 \mathrm{~nm}$, the new peak with a redshift and color enhancement is observed with prolonged processing time. The redshift phenomenon is caused by the conjugate effect and the influence of $\mathrm{pH}$ on the UV/Vis spectra, thereby changing the molecular properties. In accordance with the Beer-Lambert law, the total absorbance of the UV/Vis spectra can be obtained by integrating the absorbance area at the wavelength from 190 to $340 \mathrm{~nm}$. A large total absorbance results in a high concentration of RONS in PAW.

Calculation and comparison show that a high voltage and small needle-dielectric plate distance result in high total absorbance, which is in accordance with the above conclusion. Moreover, the RONS of PAW prepared with the needle array-plate DBD are higher than those of discharge 

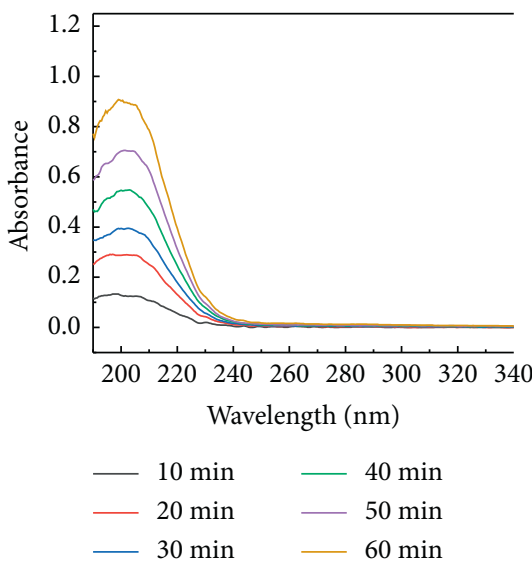

(a)



$\begin{array}{ll}-10 \mathrm{~min} & -40 \mathrm{~min} \\ -20 \mathrm{~min} & -50 \mathrm{~min} \\ -30 \mathrm{~min} & -60 \mathrm{~min}\end{array}$

(d)
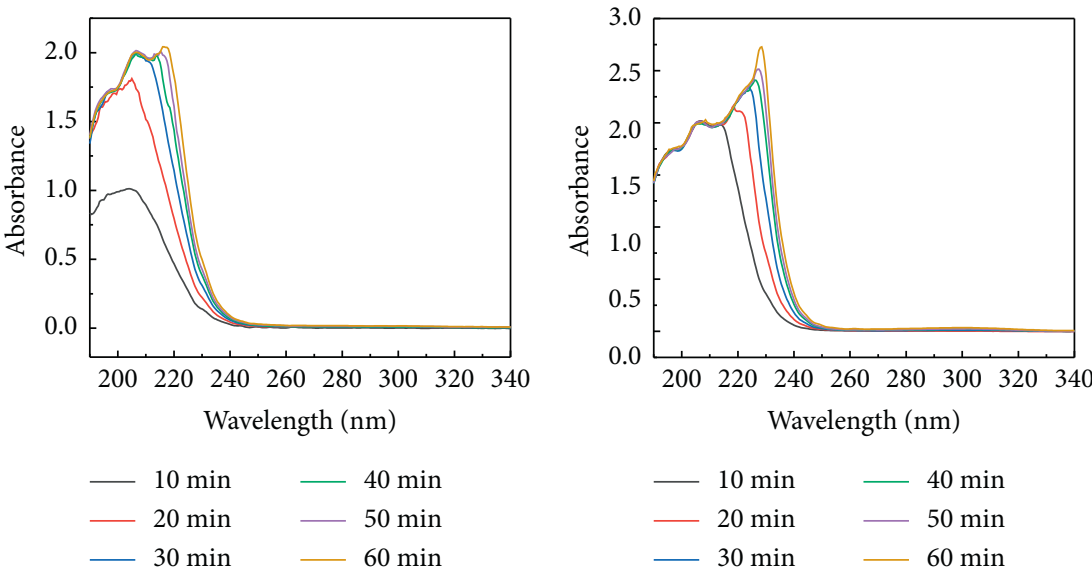

(b)

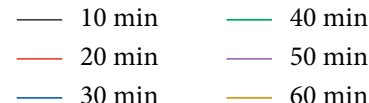

(c)
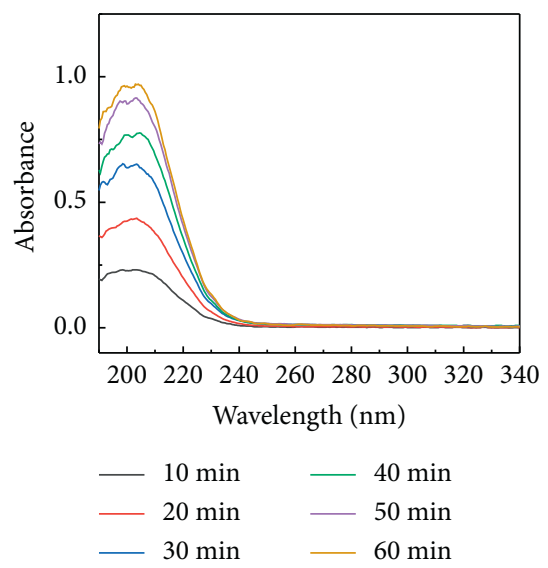

(e)

FIGURE 10: UV/Vis spectra at the needle-dielectric plate distance of $4 \mathrm{~cm}$ and voltages of (a) 15 , (b) 20 , and (c) $25 \mathrm{kV}$. UV/Vis spectra at a voltage of $20 \mathrm{kV}$ and the needle-dielectric plate distance of (d) 3 and (e) $5 \mathrm{~cm}$.

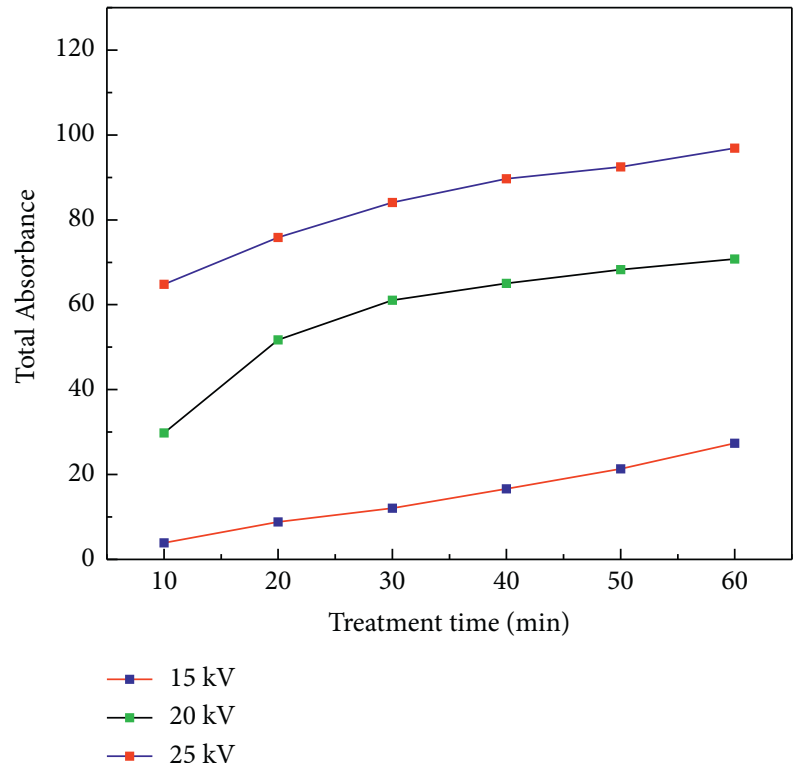

(a)

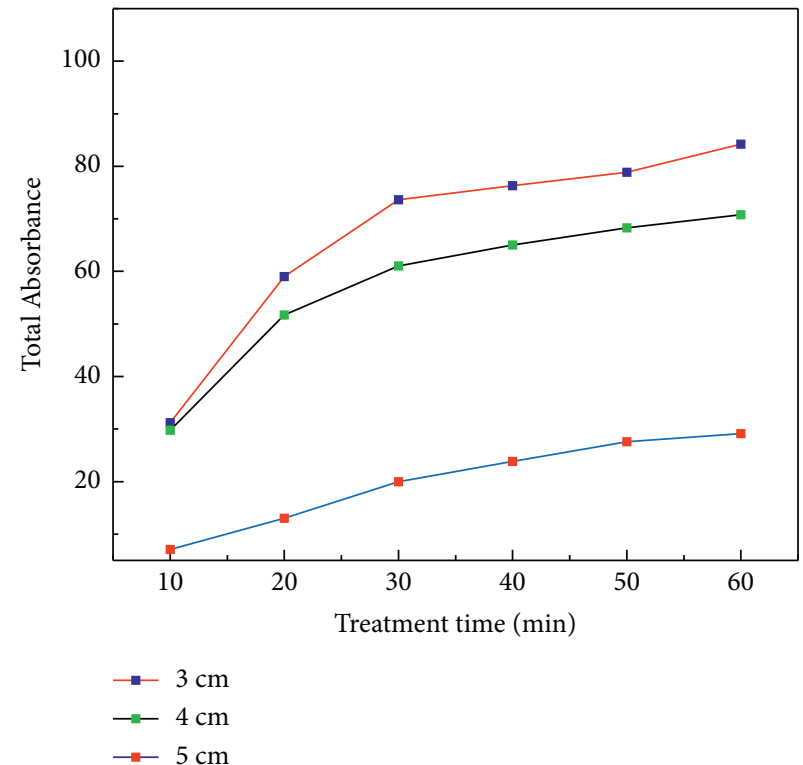

(b)

Figure 11: Total absorbance values at (a) voltages of 15,20 , and $25 \mathrm{kV}$ and the needle-dielectric plate distance of $4 \mathrm{~cm}$ and (b) voltage of $20 \mathrm{kV}$ and the needle-dielectric plate distance of 3,4 , and $5 \mathrm{~cm}$. 


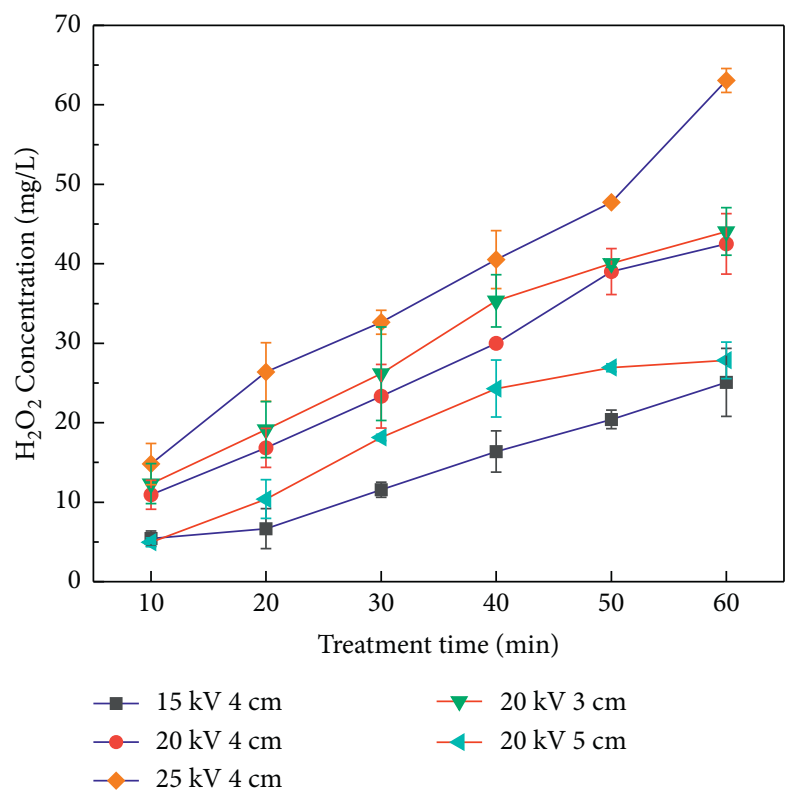

Figure 12: $\mathrm{H}_{2} \mathrm{O}_{2}$ concentrations at voltages of 15,20 , and $25 \mathrm{kV}$ and the needle-dielectric plate distance of $4 \mathrm{~cm}$ and the needle-dielectric plate distance of 3 and $5 \mathrm{~cm}$ and voltage of $20 \mathrm{kV}$.



(a)

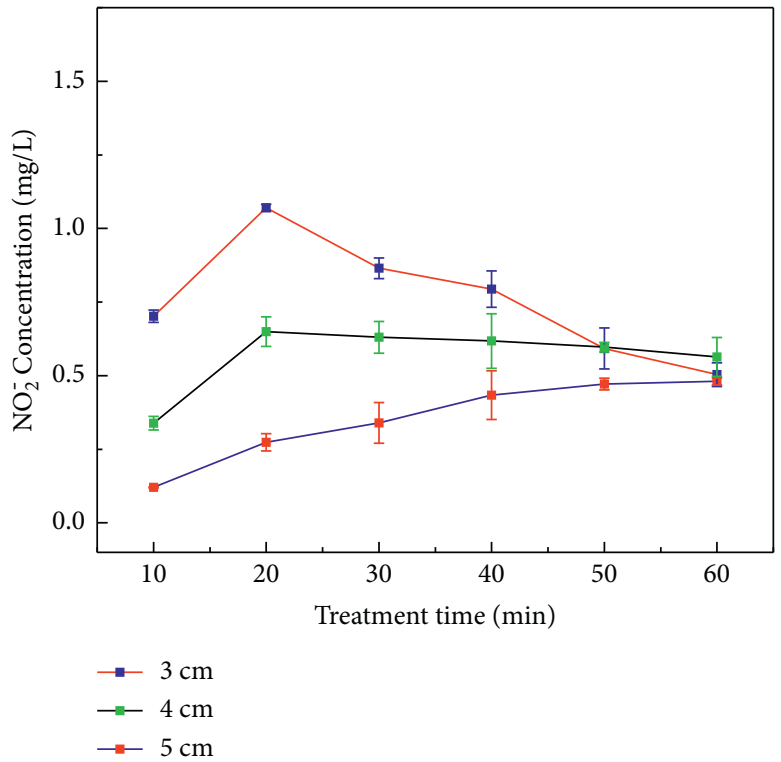

(b)

Figure 13: $\mathrm{NO}_{2}^{-}$concentrations at (a) voltages of 15,20 , and $25 \mathrm{kV}$ and the needle-dielectric plate distance of $4 \mathrm{~cm}$ and (b) the needledielectric plate distance of 3,4 , and $5 \mathrm{~cm}$ and voltage of $20 \mathrm{kV}$.

devices used in previous studies. The concentrations of $\mathrm{H}_{2} \mathrm{O}_{2}$ and $\mathrm{NO}_{3}^{-}$increase with increasing voltage, proximity of the needle-dielectric plate distance, and treatment time. In the study of Liu et al., the maximum concentrations of $\mathrm{H}_{2} \mathrm{O}_{2}$ and $\mathrm{NO}_{3}^{-}$can reach 2.2 and $9 \mathrm{mg} / \mathrm{L}$, respectively [27]. In the study of Oh et al., the concentration of $\mathrm{H}_{2} \mathrm{O}_{2}$ is always below $1 \mathrm{mg} /$ $\mathrm{L}$, and the highest concentration of $\mathrm{NO}_{3}^{-}$is around $0.5 \mathrm{mg} / \mathrm{L}$ [31]. However, the concentration of the experimental device we used can reach $5 \mathrm{mg} / \mathrm{L}$ at the lowest level when the water is activated for $10 \mathrm{~min}$ and can reach $63 \mathrm{mg} / \mathrm{L}$ after long- term treatment. The concentration of $\mathrm{NO}_{2}^{-}$is different from those of $\mathrm{H}_{2} \mathrm{O}_{2}$ and $\mathrm{NO}_{3}^{-}$in the change trend. The UV/Vis spectra analysis shows that at the needle-dielectric plate distance of 3 and $4 \mathrm{~cm}$, voltage of $20 \mathrm{kV}$, and short treatment time, the UV/Vis spectra of PAW only show a peak at the wavelength of $203 \mathrm{~nm}$. At this time, the concentration of $\mathrm{NO}_{2}^{-}$increases with the extension of treatment time. After treatment for more than 20 min, peak changes in the UV/Vis spectra, redshift, and enhancement phenomena are observed, and the concentration of $\mathrm{NO}_{2}^{-}$decreases with 


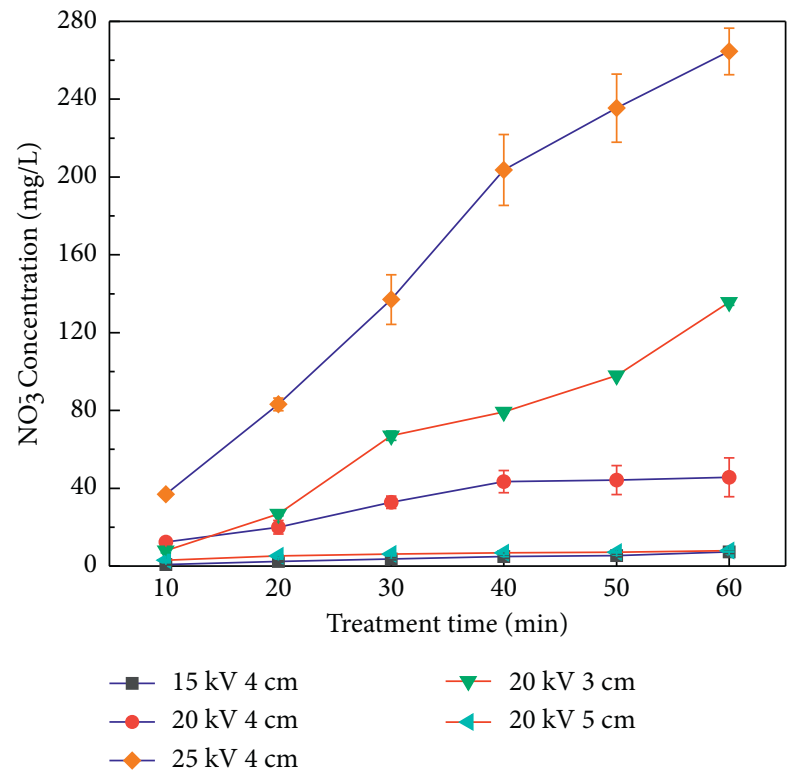

Figure 14: $\mathrm{NO}_{3}^{-}$concentrations at voltages of 15,20 , and $25 \mathrm{kV}$ and the needle-dielectric plate distance of $4 \mathrm{~cm}$ and the needle-dielectric plate distance of 3,4 , and $5 \mathrm{~cm}$ and voltage of $20 \mathrm{kV}$.

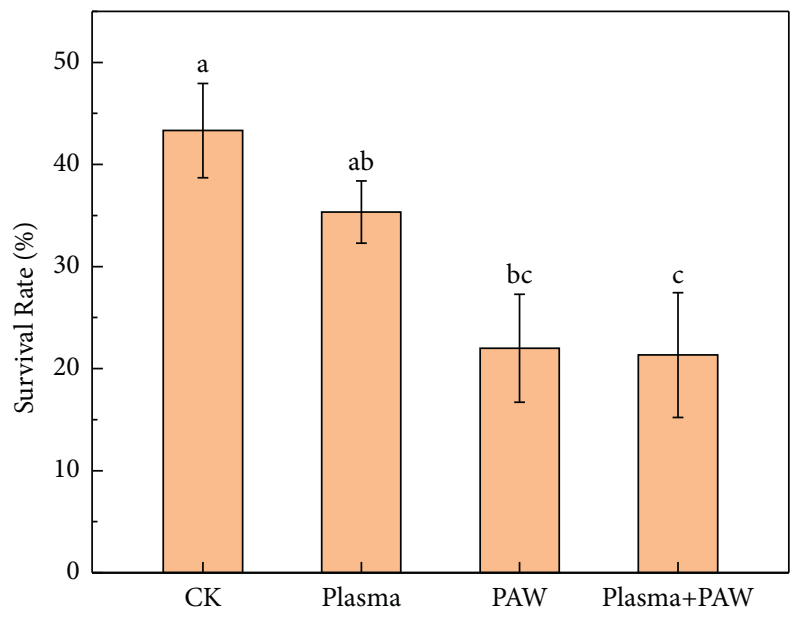

Figure 15: Survival rate of Astragalus adsurgens Pall (different letters indicate statistically significant differences between treatments $(p<0.05))$.

increasing treatment time. When the needle-dielectric plate distance is $4 \mathrm{~cm}$ and the voltage is $25 \mathrm{kV}$, the $\mathrm{UV} / \mathrm{V}$ is spectra change beginning from the treatment of $10 \mathrm{~min}$, and the concentration decreases with increasing treatment time. This result may be because the activation is evident due to high voltage, close needle-dielectric plate distance, and long treatment time. When $\mathrm{H}_{2} \mathrm{O}_{2}$ and $\mathrm{NO}_{2}^{-}$reach a certain concentration, the oxidation-reduction reaction occurs to generate $\mathrm{NO}_{3}^{-}$and $\mathrm{H}_{2} \mathrm{O}$. Thus, the concentration of $\mathrm{NO}_{2}^{-}$ decreases.

It is generally believed that the seeds treated by discharge plasma or PAW can promote the growth and germination rate of plants, but there is no significant difference in the final survival rate of seeds [20, 21, 32]; therefore, it is impossible to use discharge plasma for

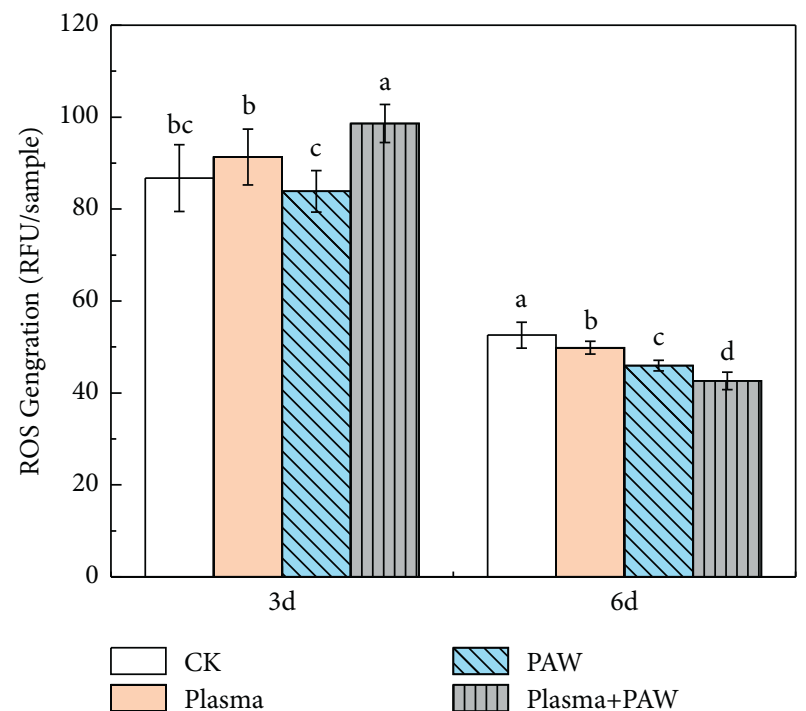

FIgURE 16: Content of reactive oxygen species in Astragalus adsurgens Pall seedlings (different letters indicate statistically significant differences between treatments $(p<0.05))$.

mutation breeding. Especially for the seeds of $A$. adsurgens Pall, because there is a dense wax layer on the epidermis, the discharge plasma can hardly penetrate the seed coat and reach the embryo; however, after discharge plasma etching, RONS in the PAW can reach the embryo site during the seed germination and growth process, and a series of complex processes occur, which can achieve the purpose of mutation breeding. Studies have shown that the growth of $A$. adsurgens Pall was obviously inhibited by PAW with voltage of $25 \mathrm{kV}$, the needle-dielectric plate distance of $4 \mathrm{~cm}$, and activation time of $60 \mathrm{~min}$. The combined treatment of PAW and 
discharge plasma had a significant effect on the seeds, which reduced the growth activity of $A$. adsurgens Pall and led to slow growth of it. Meanwhile, the survival of A. adsurgens Pall seeds treated by PAW was less than half lethal. Studies have shown that ROS plays an important role in cell proliferation, differentiation, and apoptosis and has the function of signaling molecules. ROS is an important marker connecting physical and biological interpretation of the connection of the electromagnetic causal chain. After the plasma and PAW treatment, the ROS generated in the cell matrix enters the cell and interacts with the macromolecules in the cell, thus changing the metabolic activity and genetic characteristics of cells [33]. Under the synergetic effect of plasma and PAW, plants are stimulated by the outside world, and a large amount of ROS will accumulate in the plants in a short time, which will break the balance of ROS and its scavenging system, namely the protective enzyme system; it caused serious oxidative stress damage and reduced the survival rate of seedlings. After inoculation for a long time, the treatment group was stimulated by external stimuli, and the accumulation of ROS in the body caused the activity of the scavenging system. The ROS concentration of Plasma + PAW decreased significantly after 6 days of inoculation. The survival rate and ROS concentration data of $A$. adsurgens Pall showed that too high or too low ROS concentration could inhibit seed germination. The synergistic effect of discharge plasma and PAW can be applied to the mutation breeding of A. adsurgens Pall. It is of great significance to the mutation breeding of $A$. adsurgens Pall.

\section{Conclusions}

(1) The plasma generated by the needle array-plate DBD device has a large concentration and rich types. Increasing voltage and decreasing needle-dielectric plate distance result in increased plasma concentration and ionic wind speed.

(2) Increased ionic wind speed can accelerate water evaporation and increase the concentration of RONS in PAW. During the treatment process, ionic wind and water collide form ripples on the water surface. Many RONS are dissolved in water and react with water due to the fluctuation in water. This activation effect is more pronounced than that of discharge plasma acting directly on water to activate it.

(3) The high concentration of discharge plasma and the long processing time lead to the change in the peak at $190-210 \mathrm{~nm}$ in the UV/Vis spectra. The redshift phenomenon and color enhancement occur at wavelengths higher than $210 \mathrm{~nm}$, and the chemical reaction occurs in PAW.

(4) The combined action of discharge plasma and PAW increased the seed mortality rate and the ROS level of seedlings significantly. It caused severe oxidative stress injury, the survival rate decreased significantly and reached below the half lethal dose. It is of great significance to the mutation breeding of $A$. adsurgens Pall.

\section{Data Availability}

The data are available from the corresponding author upon request.

\section{Conflicts of Interest}

The authors declare that there are no conflicts of interest regarding the publication of this paper.

\section{Acknowledgments}

This research was funded by the National Natural Science Foundation of China (Nos. 51767020 and 52067017), Inner Mongolia Autonomous Region Science and Technology Plan Project (No. 2020GG0280), and Natural Science Foundation of Inner Mongolia Autonomous Region (Nos. 2019MS06025 and 2020MS01016).

\section{References}

[1] Y. S. Jin, C. Cho, D. Kim et al., "Mass production of plasma activated water by an atmospheric pressure plasma," Japanese Journal of Applied Physics, vol. 59, Article ID SHHF05, 2020.

[2] L. Guo, Z. Yao, L. Yang et al., "Plasma-activated water: an alternative disinfectant for $S$ protein inactivation to prevent SARS-CoV-2 infection," Chemical Engineering Journal, vol. 421, Article ID 127742, 2020.

[3] C. Bradu, K. Kutasi, M. Magureanu et al., "Reactive nitrogen species in plasma-activated water: generation, chemistry and application in agriculture," Journal of Physics D: Applied Physics, vol. 53, no. 21, 2020.

[4] N. K. Kaushik, B. Ghimire, Y. Li et al., "Biological and medical applications of plasma-activated media, water and solutions," Biological Chemistry, vol. 400, no. 1, pp. 39-62, 2018.

[5] N. Puač, M. Gherardi, and M. Shiratani, "Plasma agriculture: a rapidly emerging field," Plasma Processes and Polymers, vol. 15, 2018.

[6] E. J. Rifna, K. Ratish Ramanan, and R. Mahendran, "Emerging technology applications for improving seed germination," Trends in Food Science \& Technology, vol. 86, pp. 95-108, 2019.

[7] T. Maisch, T. Shimizu, Y.-F. Li et al., "Decolonisation of MRSA, S. aureus and E. coli by cold-atmospheric plasma using a porcine skin model in vitro," PLoS One, vol. 7, no. 4, Article ID e34610, 2012.

[8] X. Gao, A. Zhang, P. Héroux et al., "Effect of dielectric barrier discharge cold plasma on pea seed growth," Journal of Agricultural and Food Chemistry, vol. 67, no. 39, pp. 1081310822, 2019.

[9] K. Kučerová, M. Henselová, Ľ. Slováková et al., "Effects of plasma activated water on wheat: germination, growth parameters, photosynthetic pigments, soluble protein content, and antioxidant enzymes activity," Plasma Processes and Polymers, vol. 16, Article ID e1800131, 2019.

[10] F. Judée, S. Simon, C. Bailly, and T. Dufour, "Plasma-activation of tap water using $\mathrm{DBD}$ for agronomy applications: identification and quantification of long lifetime chemical species and production/consumption mechanisms," Water Research, vol. 133, pp. 47-59, 2018. 
[11] Q. Zhang, Y. Liang, H. Feng et al., "A study of oxidative stress induced by non-thermal plasma-activated water for bacterial damage," Applied Physics Letters, vol. 102, no. 20, Article ID 203701, 2013.

[12] Z. Xiao-Yan, L. Hai-Lan, W. Di et al., "The inhibitory effect of plasma activated water on Fusarium oxysporum of green pepper," Modern Food Science and Technology, vol. 36, 2020.

[13] Z. Chen, D. Liu, C. Chen et al., "Analysis of the production mechanism of $\mathrm{H} 2 \mathrm{O} 2$ in water treated by helium DC plasma jets," Journal of Physics D: Applied Physics, vol. 51, no. 32, Article ID 325201, 2018.

[14] Z. Chen, D. Liu, H. Xu et al., "Decoupling analysis of the production mechanism of aqueous reactive species induced by a helium plasma jet," Plasma Sources Science and Technology, vol. 28, no. 2, Article ID 025001, 2019.

[15] Z. C. Liu, D. X. Liu, C. Chen et al., "Physicochemical processes in the indirect interaction between surface air plasma and deionized water," Journal of Physics D: Applied Physics, vol. 48, no. 49, Article ID 495201, 2015.

[16] D. X. Liu, Z. C. Liu, C. Chen et al., "Aqueous reactive species induced by a surface air discharge: heterogeneous mass transfer and liquid chemistry pathways," Scientific Reports, vol. 6, no. 1, p. 23737, 2016.

[17] Z. C. Liu, L. Guo, D. X. Liu et al., "Chemical kinetics and reactive species in normal saline activated by a surface air discharge," Plasma Processes and Polymers, vol. 14, pp. 4-5, 2017.

[18] C. A. Jr . and F. L. G. D. Menezes, "Effect of plasma-activated water on soaking, germination, and vigor of Erythrina velutina seeds," Plasma Medicine, vol. 9, no. 2, pp. 111-112, 2019.

[19] M. El Shaer, H. El Welily, A. Zaki et al., "Germination of wheat seeds exposed to cold atmospheric plasma in dry and wet plasma-activated water and mist," Plasma Medicine, vol. 10, no. 1, pp. 1-13, 2020.

[20] W. Xu, Z. Song, X. Luan, C. Ding, Z. Cao, and X. Ma, "Biological effects of high-voltage electric field treatment of naked oat seeds," Applied Sciences, vol. 9, no. 18, p. 3829, 2019.

[21] X. Luan, Z. Song, W. Xu, Y. Li, C. Ding, and H. Chen, "Spectral characteristics on increasing hydrophilicity of Alfalfa seeds treated with alternating current corona discharge field," Spectrochimica Acta Part A: Molecular and Biomolecular Spectroscopy, vol. 236, p. 118350, 2020.

[22] J. Ni, C. Ding, Y. Zhang, Z Song, X Hu, and T Hao, "Electrohydrodynamic drying of Chinese wolfberry in a multiple needle-to-plate electrode system," Foods, vol. 8, no. 152, 2019.

[23] J. Ni, C. Ding, Y. Zhang, and Z. Song, "Impact of different pretreatment methods on drying characteristics and microstructure of goji berry under electrohydrodynamic (EHD) drying process," Innovative Food Science \& Emerging Technologies, vol. 61, Article ID 102318, 2020.

[24] Y. Zhang, C. Ding, J. Ni et al., "Effects of high-voltage electric field process parameters on the water-holding capacity of frozen beef during thawing process," Journal of Food Quality, vol. 2019, Article ID 9140179, 11 pages, 2019.

[25] J.-S. Oh, E. J. Szili, K. Ogawa et al., "UV-vis spectroscopy study of plasma-activated water: dependence of the chemical composition on plasma exposure time and treatment distance," Japanese Journal of Applied Physics, vol. 57, no. 1, Article ID 0102B9, 2018.

[26] E. J. Szili, J.-S. Oh, S.-H. Hong, A. Hatta, and R. D. Short, "Probing the transport of plasma-generated RONS in an agarose target as surrogate for real tissue: dependency on time, distance and material composition," Journal of Physics D: Applied Physics, vol. 48, no. 20, Article ID 202001, 2015.

[27] Z. Liu, C. Zhou, D. Liu et al., "Quantifying the concentration and penetration depth of long-lived RONS in plasma-activated water by UV absorption spectroscopy," AIP Advances, vol. 9, no. 1, Article ID 015014, 2019.

[28] T. S. Babu, T. A. Akhtar, M. A. Lampi, S. Tripuranthakam, D. G. Dixon, and B. M. Greenberg, "Similar stress responses are elicited by copper and ultraviolet radiation in the aquatic plant lemna gibba: implication of reactive oxygen species as common signals," Plant and Cell Physiology, vol. 44, no. 12, pp. 1320-1329, 2003.

[29] X. L. Deng, A. Y. Nikiforov, P. Vanraes, and C. Leys, "Direct current plasma jet at atmospheric pressure operating in nitrogen and air," Journal of Applied Physics, vol. 113, no. 2, Article ID 023305, 2013.

[30] T. Czech, A. T. Sobczyk, and A. Jaworek, "Optical emission spectroscopy of point-plane corona and back-corona discharges in air," The European Physical Journal D, vol. 65, no. 3, pp. 459-474, 2011.

[31] E. J. Szili, J.-S. Oh, S.-H. Hong et al., "Probing the transport of plasma-generated RONS in an agarose target as surrogate for real tissue: dependency on time, distance and material composition," Journal of Physics D: Applied Physics, vol. 49, p. 304005, 2016.

[32] L.. Holubová, S. Kyzek, I. Ďurovcová et al., "Non-thermal plasma-A new green priming agent for plants?" International Journal of Molecular Sciences, vol. 21, no. 24, p. 9466, 2020.

[33] S. Zhiqing, D. Changjiang, L. Xinyu et al., "Review on the biological effect of high voltage corona electric field," Journal of Nuclear Agricultural Sciences, vol. 33, no. 1, 2019. 